\title{
Multidisciplinary Therapy for Locally Advanced Oesophageal Cancer With Special Reference to Surgical Conversion and Salvage
}

\author{
MAKOTO SOHDA, TATSUYA MIYAZAKI, MAKOTO SAKAI, YUJI KUMAKURA, \\ HIROAKI HONJYO, KEIGO HARA, NARITAKA TANAKA, TAKEHIKO YOKOBORI and KEN SHIRABE \\ Department of General Surgical Science, Gunma University Graduate School of Medicine, Gunma, Japan
}

\begin{abstract}
Background/Aim: Unresectable oesophageal cancer with surrounding invasion carries a particularly poor prognosis. The chemoradiotherapy treatment for locally-unresectable oesophageal cancer aims to initially control local invasion before proceeding to the next treatment, and is ideally used with curative intent. The aim of this study was to investigate patient treatment course and survival to determine the best treatment and evaluate surgical intervention for these advanced cancers. Patients and Methods: A total of 147 patients who were diagnosed with clinical T4b oesophageal cancer were included in this study. Results: Forty-three patients had undergone curative resection of the tumour and surrounding invasion at midterm evaluation, 104 patients continued with definitive chemoradiotherapy, and salvage surgery was performed in 21 patients. Multivariate analysis of disease-specific survival showed that response at the midterm evaluation and surgical intervention (conversion surgery + salvage surgery) were significant prognostic factors. Conclusion: Surgical intervention was an independent prognostic factor, and operation should be performed in eligible patients after considering the risks and proper timing.
\end{abstract}

Oesophageal cancer is the sixth-leading cause of cancerrelated mortality worldwide because of its high malignant potential and poor prognosis (1). The prognosis of this cancer is one of the worst among malignant digestive neoplasms because of its aggressive tumour biology and

Correspondence to: Makoto Sohda, MD, $\mathrm{PhD}$, Department of General Surgical Science, Gunma University Graduate School of Medicine, 3-39-22, Showa-machi, Maebashi, Gunma 371-8511, Japan. Tel: +81 272208224, Fax: +81 272208230, e-mail: msohda@ gunma-u.ac.jp

Key Words: Advanced oesophageal cancer, surgery, response. delayed detection of early oesophageal cancer. Standard therapy for locally-advanced, but resectable squamous cell carcinoma of the oesophagus is neoadjuvant chemotherapy or chemoradiotherapy followed by surgery or definitive chemoradiotherapy. However, oesophageal cancers have an increased tendency to invade adjacent organs, such as the trachea, lungs, heart and aorta, because of the lack of serosa in the oesophagus. A study comparing the effect of surgery alone or neoadjuvant chemoradiation plus surgery demonstrated an increased survival benefit in the latter case (2). However, the chemoradiotherapy treatment strategy for clinical stage $\mathrm{T} 4 \mathrm{~b}$ (cT4b) aims initially to control local invasion before proceeding to the next treatment, and is ideally curative. Bedenne et al. have reported no benefit with the addition of surgery after chemoradiation compared with additional chemoradiation in a large-scale randomised controlled study (FFCD 9102) (3). Moreover, Stahl et al. have conducted a randomized controlled trial and reported that adding surgery to chemoradiotherapy improves local tumour control but it does not increase survival in patients with locally-advanced oesophageal squamous cell carcinoma (4). In addition, a follow-up report of non-randomised patients in the FFCD 9102 phase III trial has shown that overall survival did not differ between responders to induction chemoradiation and patients had undergone surgery after clinical failure of chemoradiation (5). However, operable patients were included in these previous reports. Unresectable cT4b oesophageal cancer with surrounding invasion carries a particularly poor prognosis, and chemoradiotherapy is the initial treatment for this cancer at a stage without distant organ metastasis. Usually, the tumours are unresectable if peripheral invasion is not resolved by chemoradiotherapy, and the treatment strategy for cT4b oesophageal cancer without distant organ metastasis is unclear.

In this study, we investigated the possibility and significance of surgical intervention for cT4b advanced oesophageal cancer without distant organ metastasis. 


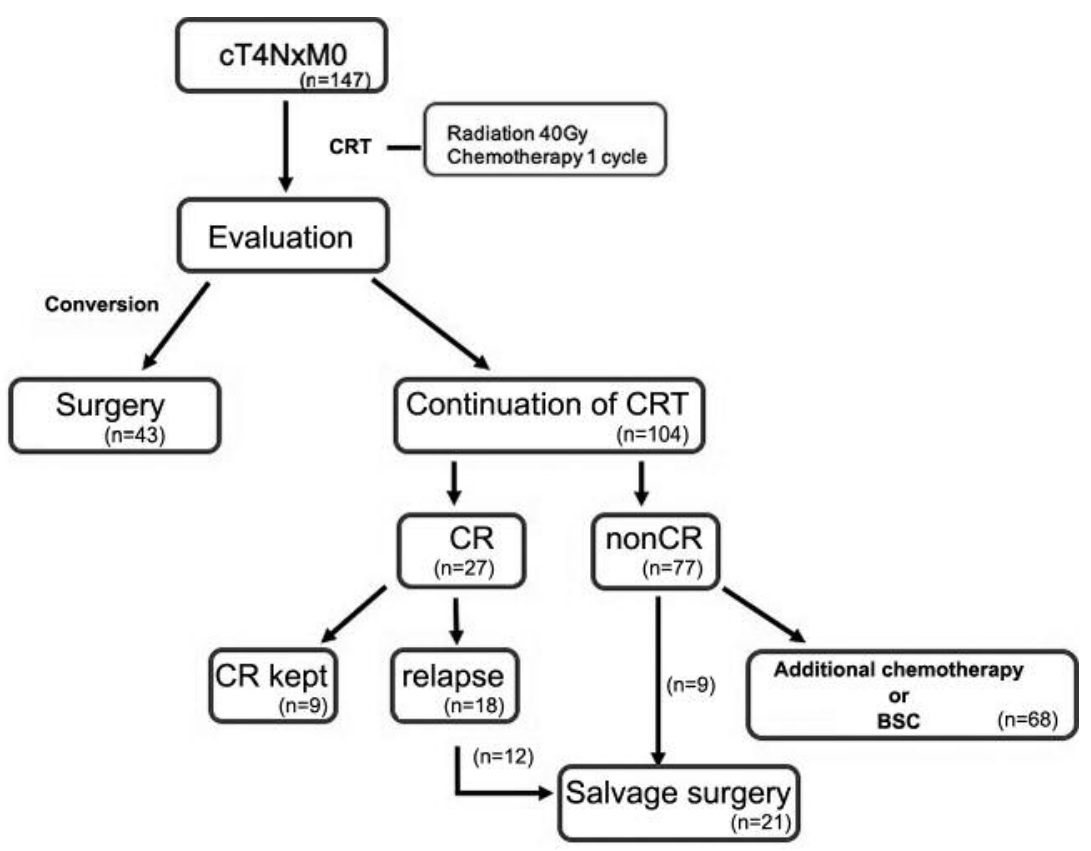

Figure 1. Treatment course for all patients with cT4b oesophageal cancer.

\section{Materials and Methods}

Patients. This was a single-centre retrospective study. Data from 147 patients (119 men and 28 women) diagnosed with cT4b oesophageal squamous cell carcinoma without distant organ metastasis at the Department of General Surgical Science, Gunma University, Gunma, Japan between November 1997 and December 2016, were evaluated. Patients with supraclavicular lymph node metastasis were included in this study. This study was approved (approved No1561) by the institutional review board of our hospital, and all patients provided written informed consent to use their data.

Treatment flow and tumour evaluation. Patients were evaluated by oesophagoscopy, computed tomography, endoscopic ultrasonography and positron emission tomography. These were performed at the time of diagnosis and preoperatively, or whenever disease recurrence was suspected. Clinical staging and pathological examination for resected specimens were performed according to the Guidelines for Clinical and Pathological Studies on Carcinoma of the Oesophagus of the Japanese Society for Oesophageal Diseases (6). The tumour stage was classified according to the seventh edition of the tumour-nodemetastasis classification system developed by the International Union Against Cancer (7). Standard clinical measurements and radiological examinations were performed to assess tumour response according to the Response Evaluation Criteria in Solid Tumours version $1.1(8)$.

Chemoradiotherapy was performed in patients with unresectable tumours invading other organs without distant organ metastasis, as an initial treatment. Following 40 Gy radiation, all patients were evaluated to determine whether peripheral invasion had resolved and whether surgical resection was an option. If curative resection was deemed possible and the patient was able to tolerate surgery, chemoradiotherapy was stopped and conversion surgery was performed after approximately 4 weeks and after obtaining adequate informed consent. Conversely, if curative resection was impossible because of insufficient tumour reduction or because the patient declined surgery, patients underwent continued chemoradiotherapy (60 Gy).

Chemoradiotherapy responses were categorized in accordance with the Guidelines for Clinical and Pathological Studies on Carcinoma of the Oesophagus of the Japanese Society for Oesophageal Diseases and Response Evaluation Criteria in Solid Tumours as complete response, partial response, stable disease and progressive disease (6). Based on the patients' clinical findings, primary tumours were classified into two groups: complete clinical response or not. Patients experiencing complete response and partial response were defined as responders, and all other patients as nonresponders according the Response Evaluation Criteria In Solid Tumours version 1.0. Surgical resection after chemoradiotherapy was performed with a curative intent. Resection was indicated for residual tumours or local recurrences of oesophageal squamous cell carcinoma.

Chemotherapy regimens. Several chemotherapeutic regimens were performed during chemoradiotherapy based on patients' histories and wishes. Docetaxel, cisplatin, and 5-fluorouracil chemotherapy in combination with radiation was performed in 59 patients (9); 39 patients underwent hyperthermochemoradiotherapy with docetaxel (10); 25 patients underwent nedaplatin plus 5fluorouracil (11) and 24 patients underwent cisplatin plus 5fluoruracil. Treatment selection was based on patients' expectations and doctors' judgement, including a pretreatment evaluation of each patient. 
Table I. Comparison of background between conversion surgery and salvage surgery.

\begin{tabular}{|c|c|c|c|}
\hline Variable & $\begin{array}{c}\text { Conversion } \\
\text { surgery } \\
(\mathrm{n}=43)\end{array}$ & $\begin{array}{l}\text { Salvage } \\
\text { surgery } \\
(n=21)\end{array}$ & $p$-Value \\
\hline Age $(\operatorname{mean} \pm$ SEM $)$ & $64.8 \pm 1.27$ & $68.6 \pm 1.82$ & 0.088 \\
\hline \multicolumn{4}{|l|}{ Gender } \\
\hline Male & 38 & 17 & \multirow[t]{2}{*}{0.432} \\
\hline Female & 5 & 4 & \\
\hline \multicolumn{4}{|l|}{ location } \\
\hline $\mathrm{Ce}$ & 1 & 4 & \multirow{4}{*}{0.026} \\
\hline Ut & 8 & 4 & \\
\hline Mt & 28 & 7 & \\
\hline Lt & 6 & 6 & \\
\hline \multicolumn{4}{|l|}{ TNM (pre CRT) } \\
\hline \multicolumn{4}{|l|}{$\mathrm{cN}$} \\
\hline 0 & 8 & 7 & \multirow{4}{*}{0.512} \\
\hline 1 & 21 & 9 & \\
\hline 2 & 13 & 4 & \\
\hline 3 & 1 & 1 & \\
\hline \multicolumn{4}{|l|}{ cM (lymph) } \\
\hline 0 & 32 & 19 & \multirow[t]{2}{*}{0.115} \\
\hline 1 & 11 & 2 & \\
\hline \multicolumn{4}{|l|}{ Stage } \\
\hline $3 \mathrm{C}$ & 32 & 19 & \multirow[t]{2}{*}{0.115} \\
\hline 4 & 11 & 2 & \\
\hline \multicolumn{4}{|c|}{ Regimen of chemotherapy } \\
\hline DCF & 18 & 4 & \multirow{4}{*}{0.001} \\
\hline $\mathrm{CF}$ & 0 & 8 & \\
\hline $\mathrm{NF}$ & 11 & 5 & \\
\hline Docetaxel & 14 & 4 & \\
\hline \multicolumn{4}{|c|}{ Preopertive comorbidity } \\
\hline \multicolumn{4}{|l|}{ Diabetes melitus } \\
\hline$(-)$ & 37 & 20 & \multirow[t]{2}{*}{0.238} \\
\hline$(+)$ & 6 & 1 & \\
\hline \multicolumn{4}{|l|}{ Reaspiratory disease } \\
\hline$(-)$ & 38 & 19 & \multirow[t]{2}{*}{0.798} \\
\hline$(+)$ & 5 & 2 & \\
\hline \multicolumn{4}{|c|}{ Cardiovascular disease } \\
\hline$(-)$ & 32 & 16 & \multirow[t]{2}{*}{0.878} \\
\hline$(+)$ & 22 & 5 & \\
\hline
\end{tabular}

SEM: Standard error of the mean.

Follow-up. Patients were assessed 1 month after completing treatment, every 3 months for the first 2 years and every 6 months thereafter. Complete response was established by oesophageal endoscopy, biopsy and computed tomography. The date of the first progression and death were recorded. The median follow-up was 21 months (range=2-144 months), and the median survival of the 147 patients was 11 months.

Statistical analysis. All statistical analyses were performed using the JMP Pro Version 14 software (SAS Institute Japan, Tokyo, Japan). Continuous data were assessed using Student's $t$-test or the MannWhitney $U$-test and categorical data using Person's Chi-square test, Fisher's exact test or the Mann-Whitney $U$-test, as appropriate. We considered $p$-values $<0.05$ to be statistically significant.
Table II. Postoperative outcome between conversion surgery and salvage surgery

\begin{tabular}{|c|c|c|c|}
\hline Variable & $\begin{array}{c}\text { Conversion } \\
\text { surgery } \\
(\mathrm{n}=43)\end{array}$ & $\begin{array}{l}\text { Salvage } \\
\text { surgery } \\
(n=21)\end{array}$ & $p$-Value \\
\hline \multicolumn{4}{|l|}{ Operative procedure } \\
\hline Mckeown & 38 & 13 & \\
\hline Ivor-Lewis & 3 & 0 & \\
\hline Tranhiatal resection & 1 & 4 & 0.007 \\
\hline Cervical esophageal resection & 1 & 2 & \\
\hline Lymphadenectomy & 0 & 2 & \\
\hline \multicolumn{4}{|l|}{ Residual tumor } \\
\hline R0 & 34 & 14 & 0.282 \\
\hline $\mathrm{R} 1$ or 2 & 9 & 7 & \\
\hline \multicolumn{4}{|l|}{ Postoperatve complication } \\
\hline \multicolumn{4}{|l|}{ Cordiovascular complication } \\
\hline$(-)$ & 33 & 19 & 0.166 \\
\hline$(+)$ & 10 & 2 & \\
\hline \multicolumn{4}{|l|}{ Pulumpnary conplicatiuon } \\
\hline$(-)$ & 36 & 14 & 0.129 \\
\hline$(+)$ & 7 & 7 & \\
\hline \multicolumn{4}{|l|}{ Anastomotic leakage } \\
\hline$(-)$ & 35 & 15 & 0.311 \\
\hline$(+)$ & 8 & 6 & \\
\hline \multicolumn{4}{|l|}{ Clavian-Dingo(CD) classification } \\
\hline$\geq 3$ & $20.0 \%$ & $35.7 \%$ & 0.056 \\
\hline \multicolumn{4}{|l|}{ Treatment related death } \\
\hline$(-)$ & 43 & 18 & 0.011 \\
\hline$(+)$ & 0 & 3 & \\
\hline
\end{tabular}

\section{Results}

Study population and treatment course. Figure 1 shows the treatment course for all 147 patients with cT4b advanced oesophageal cancer without distant organ metastasis. Curative resection was diagnosed as possible for tumours in 43 patients $(29.3 \%)$ based on resolution of surrounding invasion at the midterm evaluation. Conversely, 104 patients $(70.7 \%)$ continued with definitive chemoradiotherapy because the tumour was evaluated as impossible to resect curatively because of insufficient tumour reduction, patients were judged intolerant of surgery or patients declined surgery. At the final evaluation following definitive chemoradiotherapy, 27 patients $(18.4 \%)$ were considered as having complete response and nine of these maintained complete response with subsequent examination revealing recurrence in the remaining 18 patients $(66.7 \%)$. Twelve of the 18 patients experiencing relapse underwent salvage surgery. Seventyseven patients $(81.6 \%)$ were considered as non-responders, and nine of them, who were judged intolerant of surgery, but wished to undergo surgery, underwent salvage surgery. As a result, salvage surgery was performed in 21 patients in the definitive chemoradiotherapy group. 

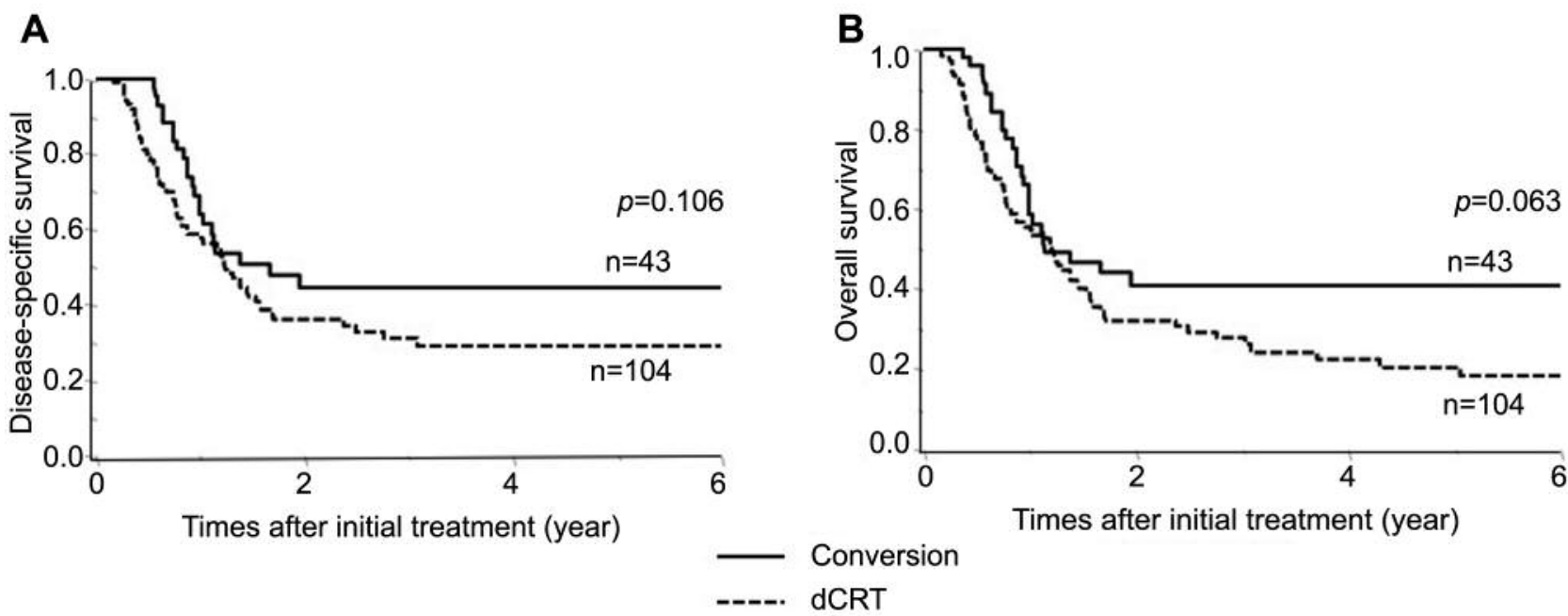

Figure 2. Survival comparison between the conversion surgery group and the definitive chemoradiotherapy group. A: Five-year disease-specific survival in the conversion group and definitive chemoradiotherapy group was $44.0 \%$ and $29.1 \%$, respectively $(p=0.106)$. B: Five-year overall survival in the conversion group and definitive chemoradiotherapy group was $40.3 \%$ and $20.4 \%$, respectively $(p=0.063)$.

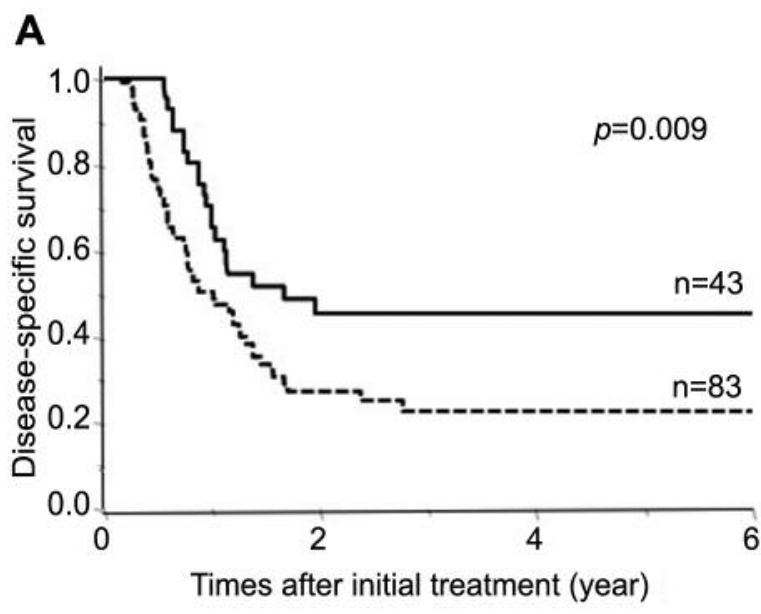

Figure 3. Survival comparison between the conversion surgery group and the definitive chemoradiotherapy group (excluding patients who underwent salvage surgery).

Comparison between patients undergoing conversion surgery with those undergoing salvage surgery. Patients who underwent conversion surgery (conversion group, $n=43$ ) were compared with patients who underwent salvage surgery (salvage group, $n=21$ ) to clarify the contribution of surgery to cT4b oesophageal cancer. Table I shows the comparison of the backgrounds of patients who underwent conversion surgery vs. salvage surgery. Regarding tumour location, the incidence of midthoracic oesophageal cancer was

\section{B}

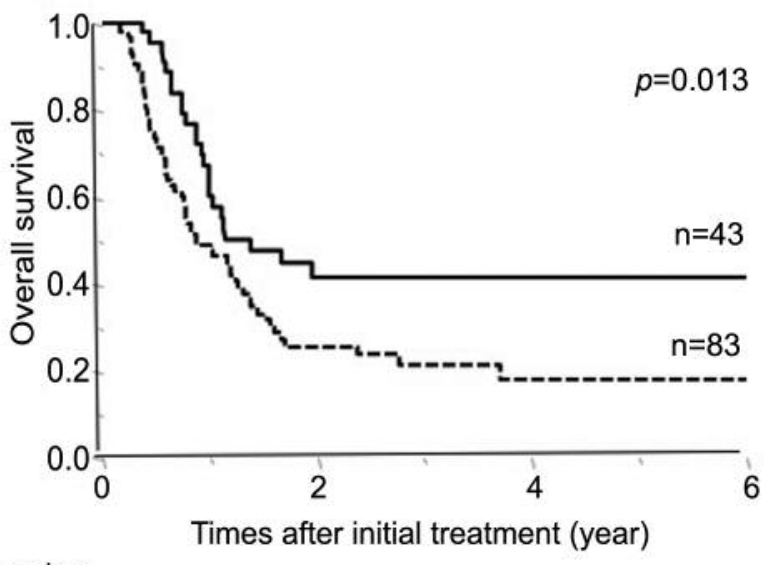

\section{Conversion}

\section{dCRT(-salvage)}


A

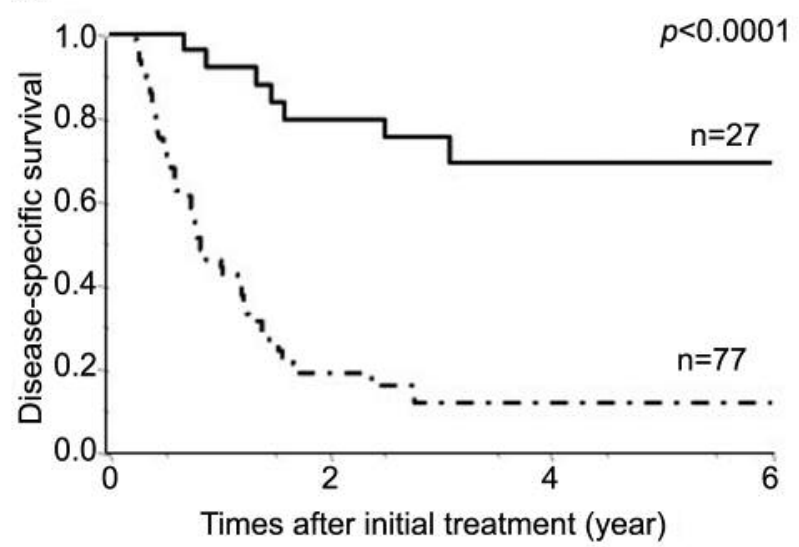

B

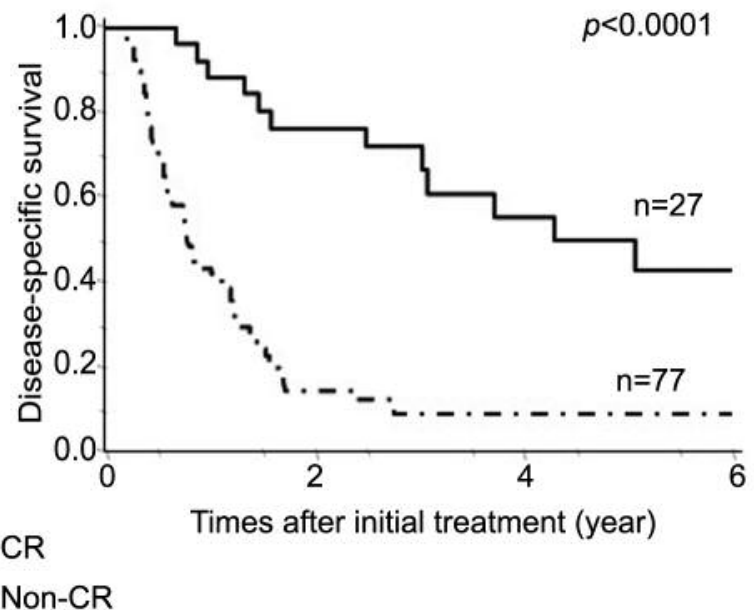

Figure 4. Survival comparison between patients achieving complete clinical response and those not achieving complete clinical response in the definitive-chemoradiotherapy group. A: Five-year disease-specific survival in the complete clinical response group and the clinical non-response group was $63.0 \%$ and $11.6 \%$, respectively $(p<0.0001)$. B: Five-year overall survival in the complete clinical response group and the clinical nonresponse group was $49.9 \%$ and $9.1 \%$, respectively $(p<0.0001)$.

A

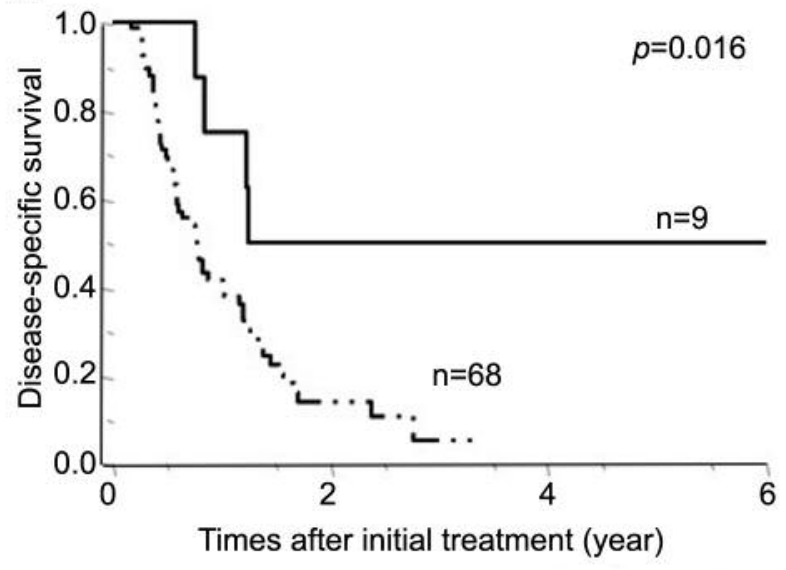

B

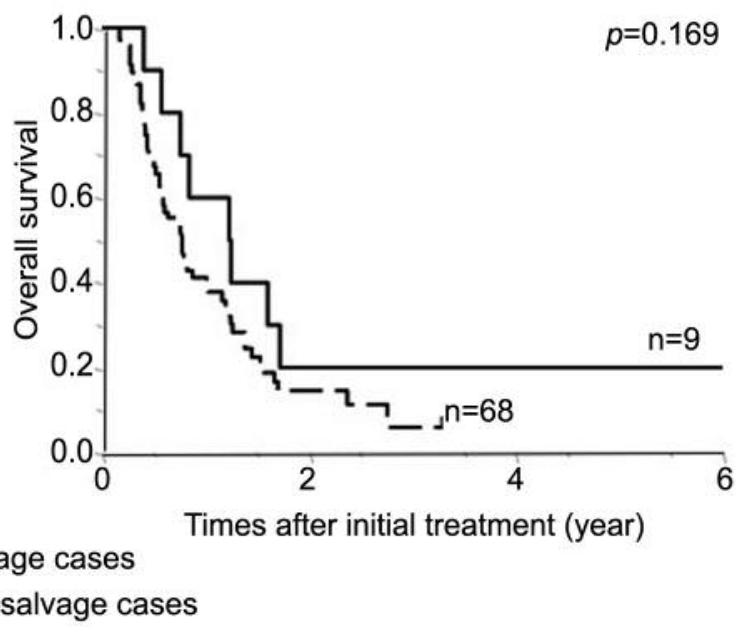

Figure 5. Survival comparison between non-responders who underwent salvage surgery and non-responders did not undergo salvage surgery in the definitive chemoradiotherapy group. Three-and 5-year disease-specific survival in the complete clinical response group and clinical non-response group were $50.0 \%$ and $5.3 \%$, and $50.0 \%$ and $0 \%$, respectively $(p<0.0001)$.

Standard surgery, including McKeown's and Ivor-Lewis' techniques was performed significantly more often in patients who underwent conversion surgery compared with those who underwent salvage surgery $(p=0.007)$. No significant differences in the rate of postoperative complications were observed between the groups; however, patients who underwent salvage surgery tended to have postoperative complication of Clavien-Dindo grade $\geq 3$ compared to the conversion-surgery group ( $20.0 \%$ vs. $35.7 \%$, respectively; $p=0.056$ ). Unfortunately, treatment-related death occurred in three patients in the salvage group. Causes of death were postoperative respiratory failure, thrombosis of the superior mesenteric artery and postoperative chylothorax.

Survival analysis. Five-years overall survival and diseasespecific survivals of all patients were $33.6 \%$ and $26.4 \%$, 


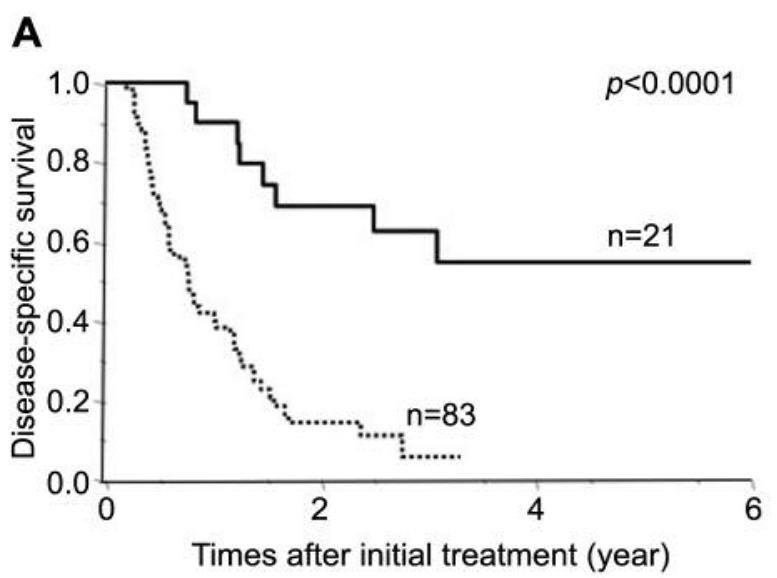

\section{B}

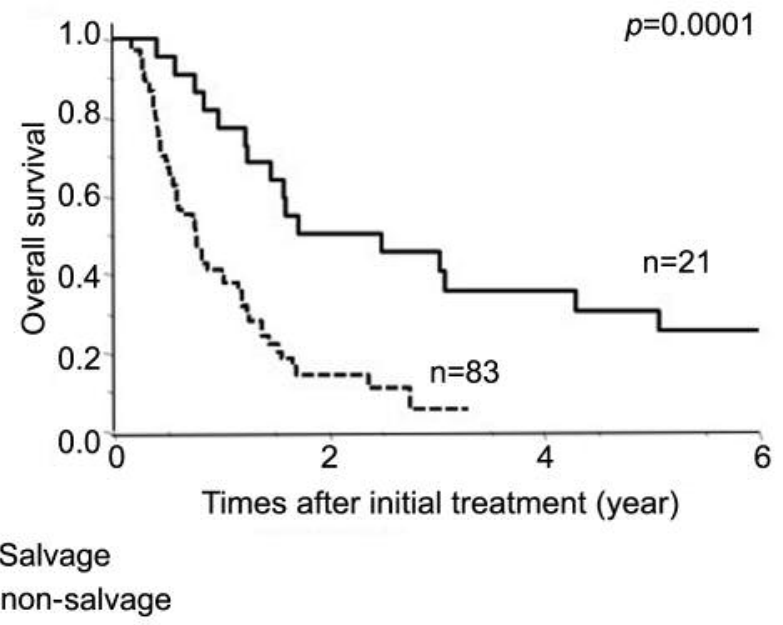

Figure 6. Survival comparison between patients who underwent salvage surgery and those who were not in the definitive-chemoradiotherapy group. A: Three- and 5-year disease-specific survival in patients undergoing salvage surgery and patients who were not were $62.5 \%$ and $5.3 \%$, and $54.8 \%$ and $0 \%$, respectively $(p<0.0001)$. B: Three- and 5-year overall survival in patients undergoing salvage surgery and patients who were not were $45.5 \%$ and $5.2 \%$, and $30.3 \%$ and $0 \%$, respectively $(p=0.0001)$.

A

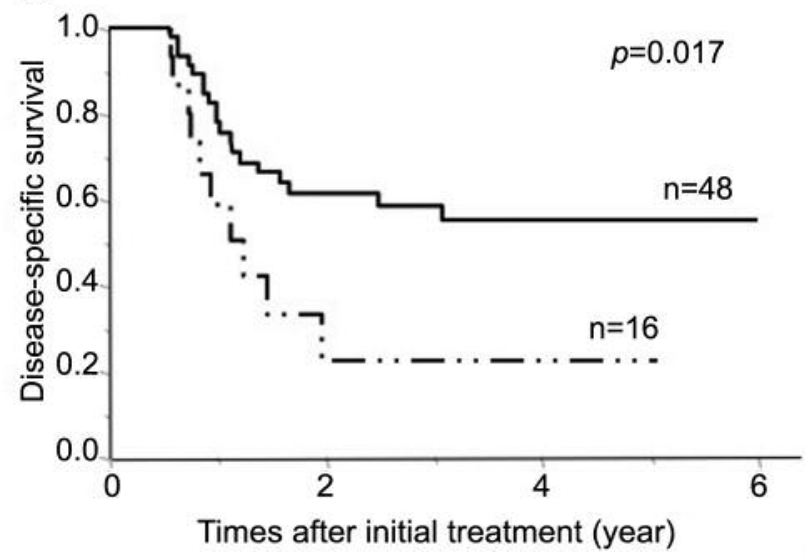

B

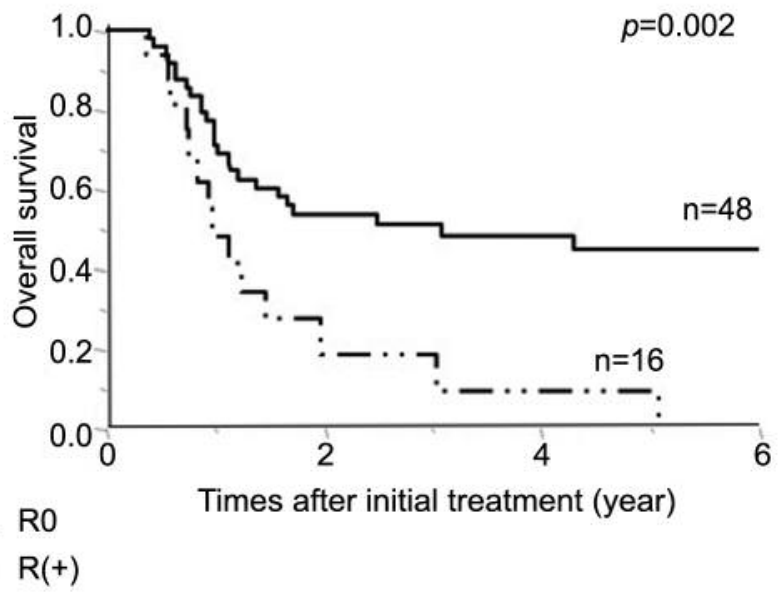

Figure 7. Survival comparison between patients who underwent $R 0$ resection and those with residual tumour in the surgical-intervention group. A: Five-year disease-specific survival in patients who underwent $R 0$ resection and in those with residual tumour was $54.8 \%$ and $22.4 \%$, respectively $(p=0.017)$. B: Three- and 5-year overall survival in patients who underwent R0 resection and in those with residual tumour were $50.7 \%$ and $9.2 \%$, and $44.6 \%$ and $0 \%$, respectively $(p=0.002)$.

respectively. Figure 2A shows the disease-specific survival for the conversion surgery group and definitive chemoradiotherapy group. The conversion surgery group had higher survival rates compared with the definitive chemoradiotherapy group, but the difference was not significant $(p=0.106)$. Similarly, the conversion surgery group tended to have higher overall survival rates compared with the definitive chemoradiotherapy group (Figure 2B; $p=0.06$ ). Figure $3 \mathrm{~A}$ and $\mathrm{B}$ show the disease-specific survival rate and overall survival rate in the conversion group and definitive chemoradiotherapy group (excluding patients undergoing salvage surgery). The 5-year disease-specific survival rate and overall survival rate in the definitive chemoradiotherapy group (excluding patients undergoing salvage surgery) were $22.8 \%$ and $17.6 \%$, respectively, and these patients had a significantly worse prognosis compared 
A

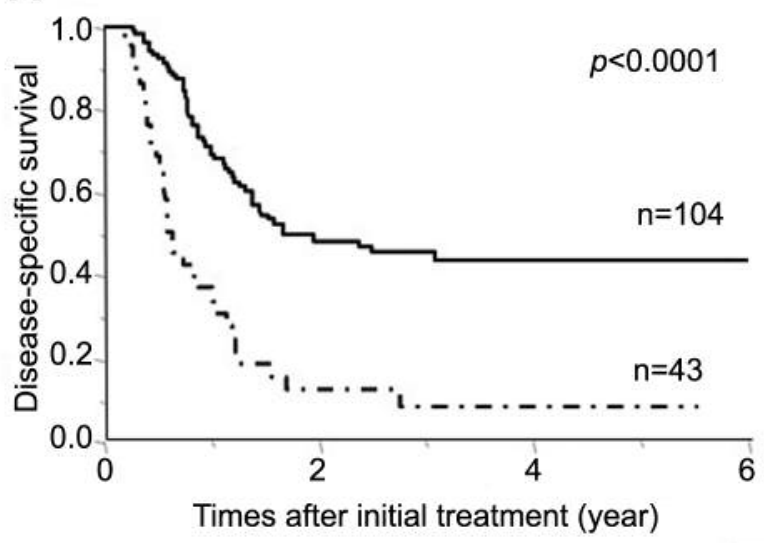

B

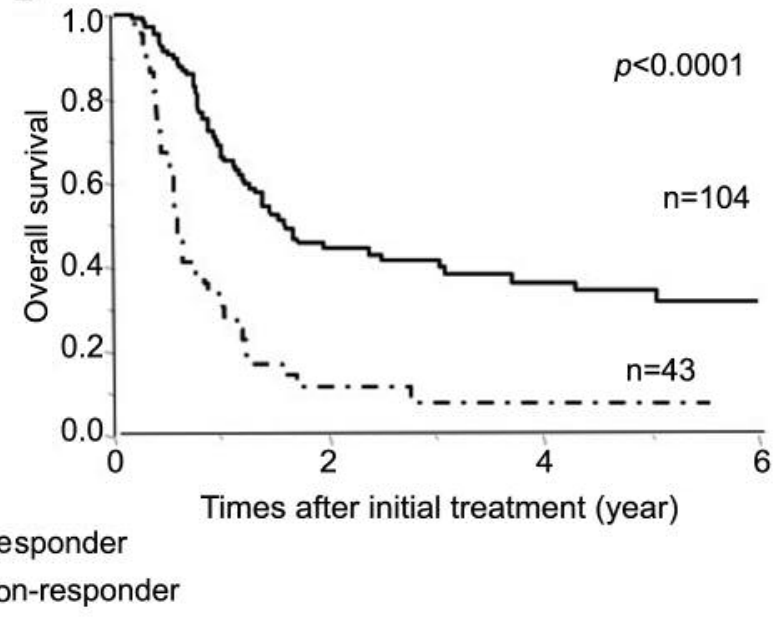

Figure 8. Survival comparison between responder and non-responder groups at the midterm evaluation. A: Five-year disease-specific survival in the responder and non-responder groups was $43.5 \%$ and $8.2 \%$, respectively $(p<0.0001)$. B: Five-year overall survival in the responder and nonresponder groups was $34.0 \%$ and $7.4 \%$, respectively $(p<0.0001)$.

Table III. Disease-specific survival.

\begin{tabular}{|c|c|c|c|c|c|c|c|c|}
\hline \multirow[t]{2}{*}{ Variable } & \multicolumn{2}{|c|}{ Reference } & \multicolumn{3}{|c|}{ Univariate analysis } & \multicolumn{3}{|c|}{ Multivariate analysis } \\
\hline & & & $\mathrm{HR}$ & $95 \% \mathrm{CI}$ & $p$-Value & HR & $95 \% \mathrm{CI}$ & $p$-Value \\
\hline $\mathrm{cN}$ & $(-)$ & $(+)$ & 0.83 & $0.415-1.492$ & 0.547 & 1.53 & $0.736-2.926$ & 0.223 \\
\hline cM (lymph) & $(-)$ & $(+)$ & 0.64 & $0.410-1.036$ & 0.069 & 0.64 & $0.402-1.549$ & 0.072 \\
\hline Mid-term evaluation & Responder & Non-responder & 0.31 & $0.198-0.479$ & $<0.001$ & 0.35 & $0.131-0.694$ & $<0.001$ \\
\hline Operatoin & $(+)$ & $(-)$ & 0.43 & $0.268-0.661$ & $<0.001$ & 0.32 & $0.153-0.734$ & 0.007 \\
\hline Conversion & $(+)$ & $(-)$ & 0.67 & $0.405-1.074$ & 0.098 & 1.60 & $0.707-4.111$ & 0.286 \\
\hline
\end{tabular}

HR: Hazard ratio; CI: confidence interval.

with the conversion group $(p=0.010$ and $p=0.013$, respectively). Moreover, patients with complete response after definitive chemoradiotherapy proved to have better prognoses than non-responders for both disease-specific- and overall survival (Figure $4 \mathrm{a}$ and $\mathrm{b} ; p<0.001$ ). In addition, nonresponders who underwent salvage surgery experienced significantly better prognosis than non-responders who did not undergo salvage surgery, regarding disease-specific survival (Figure $5 \mathrm{~A} ; p=0.016$ ). Non-responders who did not undergo salvage surgery had also extremely poor prognosis: 3 - and 5-year disease-specific survival were $5.3 \%$ and $0 \%$, respectively; however, no significant difference in overall survival were found (Figure 5B; $p=0.169$ ). In the definitive chemoradiotherapy group, disease-specific- and overall survival were significantly higher in patients who underwent salvage surgery compared with patients who did not undergo salvage surgery (Figure 6A and $\mathrm{B} ; p<0.001, p<0.001$, respectively). Moreover, patients who underwent salvage surgery for recurrence tended to have better prognosis compared with salvage surgery for patients with residual tumour $(p=0.053)$. Patients with residual tumour had significantly worse prognosis than patients who underwent R0 surgery regarding both disease-specific- and overall survival (Figure 7A and B: $p=0.017, p=0.002$, respectively). Moreover, treatment effect assessed at the midterm evaluation was significantly reflected in the prognosis, and the effect of 40 Gy radiation treatment in the responders' group was significantly higher compared with the nonresponders' group (Figure $8 ; p<0.001$ ).

Univariate analysis revealed that for patients defined as responders at the midterm evaluation, surgical intervention (conversion and salvage surgery) was significantly related to a favorable prognosis (Table III). Moreover, multivariate analysis similarly confirmed that response and surgical 
intervention were independent prognostic factors in patients who underwent chemoradiotherapy as initial treatment for cT4b oesophageal cancer (Table III).

\section{Discussion}

Treatment of advanced oesophageal cancer is difficult. For patients with local but unresectable lesions, chemoradiotherapy is the only treatment with a potentially curative intent. JCOG9516, a multicentre phase II trial, showed a $15 \%$ complete response rate and a 2 -year survival rate of $31.5 \%$ (12). The triple combination of 5fluorouracil, cisplatin, and docetaxel with concurrent irradiation for T4 and/or M1 lymph node oesophageal squamous cell carcinoma have been evaluated in a phase II study (13); however, treatment guidelines for patients not achieving complete response were lacking.

Surgical techniques and perioperative management have improved greatly. Oesophagectomy with three-field lymph node dissection contributes to improved survival compared with two-field lymph node dissection for resectable oesophageal cancer $(14,15)$. However, because surgical treatment is not the first choice for unresectable oesophageal cancer, sufficient information is needed to determine whether surgical treatment should be added for these locally-advanced oesophageal cancers. In this retrospective study, we examined the possibility and timing of surgical intervention, and whether surgical treatment contributes to improved prognosis as part of multidisciplinary treatment for cT4b oesophageal cancer. Our results showed that conversion surgery and salvage surgery contribute to improved prognosis for cT4b oesophageal cancer without distant metastasis if surgical intervention is an option. Completing curative treatment with definitive chemoradiotherapy alone is important regarding short-term surgical complications and organ preservation, although serious adverse events are possible. Stopping chemoradiotherapy and conversion surgery are also important to improve prognosis in patients with change to resectable tumours at the midterm evaluation. Salvage surgery for remnant tumours or recurrence after definitive chemoradiotherapy also improves the prognosis of patients with cT4b oesophageal cancer. The role of surgical treatment is of significant importance in prolonging survival of patients with cT4b oesophageal cancer as well as of those with resectable oesophageal cancer. Regarding operation timing, conversion surgery is considered advantageous because of the lower mortality compared with salvage surgery, although postoperative complications and prognosis do not differ between these groups. With regard to transition to surgical intervention, careful judgement is required it is ideal that complete response can be obtained by radical chemoradiotherapy, short-term fatal complications may occur due to surgery, and organ preservation cannot be performed. Moreover, it is difficult to predict a patient's subsequent course at the midterm evaluation; therefore, patients may undergo unnecessary surgery. Regardless, surgical intervention (conversion and salvage surgery) is an independent prognostic factor and, if it is an option, it should be performed after considering the risks and proper timing.

We also showed that patients with residual tumour had a significantly worse prognosis than those who underwent R0 surgery, as seen in both disease-specific and overall survival, similar to previous reports (16). R0 surgery is a very important and essential factor to improve survival in patients with cT4b cancer undergoing surgery. Therefore, an accurate diagnosis to determine whether resection is possible is important for patients who are surgical candidates.

Univariate and multivariate analysis for disease-specific survival showed that response by the midterm evaluation and surgical intervention (conversion and salvage surgery) were significant prognostic factors. This was expected because responders by the midterm evaluation are more likely to have a complete response or transition to salvage surgery following definitive chemoradiotherapy compared with nonresponders; all patients who underwent conversion surgery in our study were from the responder group.

It is interesting that the method of treatment was the most important prognostic factor for improvement than were factors related to tumour malignancy, namely, lymph node metastasis or distant lymph node metastasis, which are the usual prognostic factors in oesophageal squamous cell carcinoma. The importance of the operative procedure may be higher in patients with cT4b cancer than in those with resectable oesophageal cancer.

Studying locally-advanced oesophageal cancer is difficult, given the limited initial treatment options. Although in our study the overall number of patients was reasonable, we could not examine each treatment group in depth; therefore, larger patient numbers and future studies are needed. In addition, although our results showed that surgical intervention for unresectable oesophageal cancer significantly affected prognosis, we could not determine which surgical treatment is clinically most useful. To predict complete response at the midterm evaluation, more effective chemotherapy, establishment of an accurate assessment method for R0 resection in surgical cases and evaluation of individual risk factors that predict fatal complications, are needed. Finally, regardless of the surgical approach, surgical complications must be minimized.

\section{Conflicts of Interest}

The Authors have no financial conflicts of interest to disclose concerning the study. 


\section{Authors' Contributions}

Each author took part in the design of the study, contributed to data collection and participated in the writing of the manuscript.

\section{Acknowledgements}

The Authors would like to thank Jane Charbonneau, DVM, from Edanz Group (www.edanzediting.com/ac) for editing a draft of this manuscript.

\section{References}

1 Jemal A, Bray F, Center MM, Ferlay J, Ward E and Forman D: Global cancer statistics. CA Cancer J Clin 61: 69-90, 2014 PMID: 21296855. DOI: $10.3322 /$ caac. 20107

2 van Hagen P, Hulshof MC, van Lanschot JJ, Steyerberg EW, van Berge Henegouwen MI, Wijnhoven BP, Richel DJ, Nieuwenhuijzen GA, Hospers GA, Bonenkamp JJ, Cuesta MA, Blaisse RJ, Busch OR, ten Kate FJ, Creemers GJ, Punt CJ, Plukker JT, Verheul HM, Spillenaar Bilgen EJ, van Dekken H, van der Sangen MJ, Rozema T, Biermann K, Beukema JC, Piet AH, van Rij CM, Reinders JG, Tilanus HW and van der Gaast A; CROSS Group: Preoperative chemoradiotherapy for esophageal or junctional cancer. $\mathrm{N}$ Engl J Med 366(22): 2074-2084, 2012. PMID: 22646630. DOI: $10.1056 /$ NEJMoa1112088

3 Bedenne L, Michel P, Bouché O, Milan C, Mariette C, Conroy T, Pezet D, Roullet B, Seitz JF, Herr JP, Paillot B, Arveux P, Bonnetain $\mathrm{F}$ and Binquet $\mathrm{C}$ : Chemoradiation followed by surgery compared with chemoradiation alone in squamous cancer of the esophagus: FFCD 9102. J Clin Oncol 25(10): 1160-1168, 2007. PMID: 17401004. DOI: 10.1200/JCO.2005. 04.7118

4 Stahl M, Stuschke M, Lehmann N, Meyer HJ, Walz MK, Seeber S, Klump B, Budach W, Teichmann R, Schmitt M, Schmitt G, Franke $\mathrm{C}$ and Wilke $\mathrm{H}$ : Chemoradiation with and without surgery in patients with locally advanced squamous cell carcinoma of the esophagus. J Clin Oncol 23(10): 2310-2317, 2005. PMID: 15800321. DOI: 10.1200/JCO.2005.00.034

5 Vincent J, Mariette C, Pezet D, Huet E, Bonnetain F, Bouché O, Conroy T, Roullet B, Seitz JF, Herr JP, Di Fiore F, Jouve JL and Bedenne L; Fédération Francophone de Cancérologie Digestive (FFCD): Early surgery for failure after chemoradiation in operable thoracic oesophageal cancer. Analysis of the nonrandomised patients in FFCD 9102 phase III trial: Chemoradiation followed by surgery versus chemoradiation alone. Eur J Cancer 51(13): 1683-1693, 2015. PMID: 26163097. DOI: $10.1016 /$ j.ejca.2015.05.027

6 Japanese Society for Esophageal Disease: Guidelines for the clinical and pathological studies on carcinoma of the esophagus (11th edition). Tokyo: Kanehara, 2015.

7 Rice TW, Blackstone EH and Rusch VW: 7th edition of the AJCC Cancer Staging Manual: esophagus and esophagogastric junction. Ann Surg Oncol 17(7): 1721-1724, 2010. PMID: 20369299. DOI: 10.1245/s10434-010-1024-1
8 Eisenhauer EA, Therasse P, Bogaerts J, Schwartz LH, Sargent D, Ford R, Dancey J, Arbuck S, Gwyther S, Mooney M, Rubinstein L, Shankar L, Dodd L, Kaplan R, Lacombe D and Verweij J: New response evaluation criteria in solid tumours: revised RECIST guideline (version 1.1). Eur J Cancer 45: 228247, 2001. PMID: 19097774. DOI: 10.1016/j.ejca.2008.10.026

9 Miyazaki T, Sohda M, Tanaka N, Suzuki S, Ieta K, Sakai M, Sano A, Yokobori T, Inose T, Nakajima M, Fukuchi M, Ojima $\mathrm{H}$, Kato $\mathrm{H}$ and Kuwano $\mathrm{H}$ : Phase I/II study of docetaxel, cisplatin, and 5-fluorouracil combination chemoradiotherapy in patients with advanced esophageal cancer. Cancer Chemother Pharmacol 75(3): 449-455, 2015. PMID: 25544126. DOI: 10.1007/s00280-014-2659-6

10 Nakajima M, Kato H, Sakai M, Sano A, Miyazaki T, Sohda M, Inose T, Tanaka N, Suzuki S, Masuda N, Fukuchi M and Kuwano $\mathrm{H}$ : Planned esophagectomy after neoadjuvant hyperthermochemoradiotherapy using weekly low-dose docetaxel and hyperthermia for advanced esophageal carcinomas. Hepatogastroenterology 62(140): 887-891, 2015. PMID: 26902022.

11 Kato H, Fukuchi M, Manda R, Nakajima M, Miyazaki T, Sohda M, Masuda N, Fukai Y, Tsukada K and Kuwano H: Efficacy and toxicity of nedaplatin and 5-FU with radiation treatment for advanced esophageal carcinomas. Anticancer Res 23(4): 34933498, 2003. PMID: 12926096.

12 Ishida K, Ando N, Yamamoto S, Ide H and Shinoda M: Phase II study of cisplatin and 5-fluorouracil with concurrent radiotherapy in advanced squamous cell carcinoma of the esophagus: a Japan Esophageal Oncology Group (JEOG)/Japan Clinical Oncology Group trial (JCOG9516). Jpn J Clin Oncol 34(10): 615-619, 2004. PMID: 15591460. DOI: 10.1093/ jjco/hyh107

13 Higuchi K, Komori S, Tanabe S, Katada C, Azuma M, Ishiyama H, Sasaki T, Ishido K, Katada N, Hayakawa K and Koizumi W: Kitasato Digestive Disease and Oncology Group. Definitive chemoradiation therapy with docetaxel, cisplatin, and 5fluorouracil (DCF-R) in advanced esophageal cancer: a phase 2 trial (KDOG 0501-P2). Int J Radiat Oncol Biol Phys 89(4): 872879, 2014. PMID: 24867539. DOI: 10.1016/j.ijrobp.2014.03.030

14 Nishihira T, Hirayama K and Mori S: A prospective randomized trial of extended cervical and superior mediastinal lymphadenectomy for carcinoma of the thoracic esophagus. Am J Surg 175(1): 47-51, 1998. PMID: 9445239

15 Kato H, Tachimori Y, Watanabe H, Igaki H, Nakanishi Y and Ochiai A: Recurrent esophageal carcinoma after esophagectomy with three-field lymph node dissection. J Surg Oncol 61(4): 267272, 1996. PMID: 8627996. DOI: 10.1002/(SICI)10969098(199604)61:4<267::AID-JSO6>3.0.CO;2-8

16 Sohda M, Kumakura Y, Saito H, Kuriyama K, Yoshida T, Honjyo H, Hara K, Ozawa D, Suzuki S, Tanaka N, Sakai M, Miyazaki T, Fukuchi $\mathrm{M}$ and Kuwano $\mathrm{H}$ : Clinical significance of salvage esophagectomy for patients with esophageal cancer and factors of influencing long-term survival. Anticancer Res 37(9): 5045-5051, 2007. PMID: 28870932. DOI: 10.21873/anticanres. 11920

Received April 10, 2019

Revised May 16, 2019

Accepted May 17, 2019 